\title{
Biomaterials
}

\section{Properties of the poly(vinyl alcohol)/chitosan blend and its effect on the culture of fibroblast in vitro}

\author{
Wen-Yuan Chuang ${ }^{\mathrm{a}}$, Tai-Horng Young ${ }^{\mathrm{b}, *}$, Chun-Hsu Yao ${ }^{\mathrm{c}}$, Wen-Yen Chiu ${ }^{\mathrm{a}}$ \\ ${ }^{a}$ Institute of Materials Science and Engineering, College of Engineering, National Taiwan University, Taipei, Taiwan \\ ${ }^{\mathrm{b}}$ Institute of Biomedical Engineering, College of Medicine and College of Engineering, National Taiwan University, Taipei 10016, Taiwan \\ ${ }^{\mathrm{c} D e p a r t m e n t ~ o f ~ R a d i o l o g i c a l ~ T e c h n o l o g y, ~ C h u n g t a i ~ I n s t i t u t e ~ o f ~ H e a l t h ~ S c i e n c e s ~ a n d ~ T e c h n o l o g y, ~ T a i c h a n g, ~ T a i w a n ~}$
}

Received 6 October 1998; accepted 20 March 1999

\begin{abstract}
In this work, the properties of poly(vinyl alcohol) (PVA) and PVA/chitosan blended membranes were investigated by scanning electron microscopy (SEM), differential scanning calorimetry (DSC) and electron spectroscopy for chemical analysis (ESCA). The SEM photographs show the PVA/chitosan blended membrane undergoes dramatic changes on the surface and bulk structure during the membrane formation. The DSC analysis shows that PVA and chitosan are not very compatible in the PVA/chitosan blended membrane, whereas the combination of two polymer chains of constitutionally different features is revealed. In addition, the surface of the PVA/chitosan blended membrane is enriched with nitrogen atoms at the ESCA analysis. These reflect the PVA membrane can be modified by blending with chitosan that in turn may affect the biocompatibility of the blended membrane. Therefore, adhesion and growth of fibroblasts on the PVA as well as PVA/chitosan blended membranes were investigated. Cell morphologies on the membranes were examined by SEM and cell viability was studied using MTT assay. It was observed that the PVA/chitosan blended membrane was more favorable for the cell culture than the pure PVA membrane. Cells cultured on the PVA/chitosan blended membrane had good spreading, cytoplasm webbing and flattening and were more compacting than on the pure PVA membrane. Consequently, the PVA/chitosan blended membrane may spatially mediate cellular response that can promote cell attachment and growth, indicating the PVA/chitosan blended membrane should be useful as a biomaterial for cell culture. (C) 1999 Elsevier Science Ltd. All rights reserved.
\end{abstract}

Keywords: Poly(vinyl alcohol); Chitosan; Cell culture

\section{Introduction}

Since Loeb and Sourirajan developed a method to produce asymmetric membranes [1], the field of membrane science and technology has experienced increasing growth. Recently, investigations have been performed to integrate biological cells into synthetic membranes for a variety of biomedical applications. For example, the poly(vinyl alcohol) (PVA) membranes have been developed for biomedical applications such as artificial pancreas [2-4], hemodialysis [5], synthetic vitreous [6], and implantable medical materials [7] because of their bioinertness. Therefore, the biocompatibility of materials

\footnotetext{
*Corresponding author. Tel.: + 886-2-23970800 ext. 1455; fax: + 886-2-23940049.

E-mail address: thyoung@ha.mc.ntu.edu.tw (T.-H. Young)
}

is of great importance in developing new membranes for biomedical applications. Cell cultural techniques offer a convenient system to study the biocompatibility of biomaterials under controllable conditions in vitro [8]. In fact, the interaction of cells with biomaterials has been extensively studied by using cell culture techniques [9-11].

One approach to enhance the biocompatibility of a material is to exploit the normal interaction of cells with their extracellar matrix molecules, which are often natural polymers. Chitosan is a polymer provided by nature, which is suited in principle in the medical and veterinary field $[12,13]$. For example, chitosan has a tendency to accelerate wound healing properties and the attainment of a good-looking healing skin surface [14-16]. One way to make use of chitosan consists of blending with synthetic polymer of appropriate chemical structure [17]. The morphology of polymer blends is 
often significantly affected by the interaction between the components of the blends that in turn affects also the properties of the blends. Therefore, major problems to be considered for polymer blends are miscibility. It is favorable that intermolecular interactions exist between two polymer species. This contribution is concerned with properties of the PVA/chitosan blend, and it concentrates on the influence of blend on the culture of fibroblasts. Chitosan containing hydroxyl and amine groups has therefore the potential to miscible with PVA due to the ability to form hydrogen bonds.

The properties of PVA and PVA/chitosan blended membranes were investigated by scanning electron microscopy (SEM), differential scanning calorimetry (DSC) and electron spectroscopy for chemical analysis (ESCA). In addition, it was tried to understand whether chitosan would promote the biological effects of PVA membrane in the MTT (3-[4,5-Dimethylthiazol-2-yl]2,5-diphenyltetrazolium bromide; Thiazolyl blue) assay and cell morphological observation by SEM. From the MTT assay and cells observed on these membranes, it was confirmed that modified membrane could increase the cells adhesion and growth on the polymer films.

\section{Materials and methods}

\subsection{Membrane preparation and characterization}

PVA with average molecular weight of 74800 was kindly supplied by Chang Chun Co (Taiwan). PVA was dissolved in water to form a $14 \mathrm{wt} \%$ polymer solution at $90^{\circ} \mathrm{C}$. The PVA solution was kept at $25^{\circ} \mathrm{C}$ for $24 \mathrm{~h}$ and spread on a glass plate to a uniform thickness of about $100 \mu \mathrm{m}$ by an autocoater. Subsequently, the glass plate and casting solution were immersed into a coagulation bath with $\mathrm{Na}_{2} \mathrm{SO}_{4} / \mathrm{KOH} / \mathrm{H}_{2} \mathrm{O}=$ saturated $/ 75 \mathrm{~g} /$ $1000 \mathrm{ml}$ [18] for $30 \mathrm{~min}$ to obtain a membrane ' $\mathrm{P}-1$ '. The modified membrane 'P-2' was prepared by the same procedure but with a different casting solution, which blended $2 \%(\mathrm{w} / \mathrm{v})$ solution of chitosan (crab shells, Sigma; USA) in $0.2 \mathrm{~m}$ acetic acid solution and $14 \mathrm{wt} \%$ PVA solution with a ratio of $3: 7$. The morphology of the membranes was examined using SEM after freezedried.

DSC analysis of membranes was carried out by a sensitive DSC 2010 (TA instruments Ltd., USA). The DSC was calibrated by using indium as standards. Each of the freeze-dried samples was sealed into aluminum pans, and an empty pan as a reference. The temperature was raised from room temperature at a heating rate of $10^{\circ} \mathrm{C} /$ min to observe the endothermic peak of calorimetric transition.

ESCA, also called X-ray photoelectron spectroscopy, is a surface-sensitive analysis technique. The ESCA spectra was obtained on an ESCA PHI 1600 photoelectron spectrophotometer (Physical Electronics; USA) with a magnesium anode $(\mathrm{MgK}=1253.6 \mathrm{eV})$. Polymer membranes were irradiated with photons from a soft X-ray source with a well-defined energy. The survey scan was from 0 to $1000 \mathrm{eV}$ to find the atoms of surface.

\subsection{Cell culture}

Fibroblasts were isolated from the human skin according to the conventional method by trypsinization. Culture was maintained in a $37^{\circ} \mathrm{C}$ water-jacketed incubator equilibrated with $5 \% \mathrm{CO}_{2}$ and kept at approximately $99 \%$ relative humidity. The cells were routinely grown in RPMI-1640 medium containing $10 \%$ fetal bovine serum (FBS; Gibco, USA) and 1\% antibiotic-antimycotic (Gibco, USA) in a $75 \mathrm{~cm}^{2}$ cell culture flask (Costar, USA). The cells were subcultured for about 3-day intervals with trypsin-EDTA (Gibco, USA) and used within seven to eight cycles of subculture after the primary culture.

The prepared membranes with $15 \mathrm{~mm}$ in diameter, sterilized in $70 \%$ alcohol overnight and rinsed extensively with distilled water, were placed in a 24-welled tissue culture polystyrene plates (Costar, USA). A sterilized Teflon ring $15-\mathrm{mm}$ diameter was placed on each of the tested membranes in the wells to prevent them from floating. Then the membranes were washed twice with Dulbecco's PBS. After aspiration of PBS, 1-ml medium of cell suspension at a density of $2 \times 10^{5}$ cells/ml RPMI-1640 medium was placed on each well and maintained in a humidified atmosphere with $5 \%$ $\mathrm{CO}_{2}$ at $37^{\circ} \mathrm{C}$.

For morphological observation, the cells adhering to the membrane were washed with phosphate buffered saline (PBS) after $4 \mathrm{~h}, 1$ and $4 \mathrm{~d}$ of incubation, and then fixed with $2.5 \%$ glutaraldehyde in PBS for $1 \mathrm{~h}$ at $4^{\circ} \mathrm{C}$. After thorough washing with PBS, the cells were dehydrated by graded ethanol changes and then critical point dried. The membranes were then gold sputtered in vacuum and examined by SEM.

\subsection{MTT assay}

After cell culturing for 1,2,3, and 4 days, the viability of fibroblasts was determined by MTT assay. The method of Mosmann [19] was modified and used in this study. At each period of culturing time, the $100 \mu 1$ MTT (Sigma; USA) solution was added to each well. After $3 \mathrm{~h}$ incubation at $37^{\circ} \mathrm{C}$, DMSO (dimethyl sulfoxide) of $200 \mu \mathrm{l}$ was added to dissolve the formazan crystals. The dissolvable solution was jogged homogeneously about 15 min by the shaker. The optical density of the formazan solution was read on an ELISA plate reader (ELx 800, Bio-tek) at $570 \mathrm{~nm}$. All experiments were repeated four 
times, and results are expressed as mean \pm standard deviation of mean. The differences between P-1 and P-2 membranes were evaluated by using Student's $t$-test. Significance was assessed at the $P<0.01$ level of confidence.

\section{Results and discussion}

\subsection{Characterization of membranes}

Macroscopically, P-1 and P-2 membranes appear opaque. The microscopic analyses of these two membranes are shown in Figs. 1 and 2. The P-1 membrane has a thick and dense top layer almost without any pores, which is supported by a porous sublayer similar to the so-called 'sponge structure', as shown in Fig. 1. In contrast, Fig. 2a shows the surface of P-2 membrane has significant pores. Such a porous configuration indicates that adding chitosan into the PVA solution could undergo dramatic changes on the surface structure during the membrane formation. In addition, the porous bulk of P-2 membrane is occupied by macrovoids whose walls are rough and dendritic, as shown in Fig. 2b. These suggest that PVA and chitosan are not very compatible with each other, which are further confirmed by the DSC. Therefore, the PVA membrane structure seems to be able to change by blending with chitosan, and such modification has an influence on the resulting culture of fibroblasts. This detail will be described later.

DSC curves (first scan) of chitosan, P-1 and P-2 membranes were collected in Fig. 3. In this work DSC carried out the determination of the compatibility of the blend by means of testing the endothermic peaks. PVA, the synthetic component of the blends, consists of somewhat crystalline junction zones and amorphous regions, and is a highly hydrophilic polymer, whose physical properties are strongly influenced by absorbed water. After freezedried, the glass transition temperature of the amorphous polymer fraction is seen at $75^{\circ} \mathrm{C}$ in the $\mathrm{P}-1$ membrane, common to the literature value [20]. Furthermore, a melting endothermic peak at $225^{\circ} \mathrm{C}$ is observed, associated with the crystalline polymer fraction.

In the chitosan curve, the main feature is that there is an endothermic peak at $155^{\circ} \mathrm{C}$. The presence of such endotherm could not be attributed to the liberation of sorbed moisture, since heating at $60^{\circ} \mathrm{C}$ above the glassy transition temperature (ca. $21^{\circ} \mathrm{C},[21]$ ) for $3 \mathrm{~d}$, which should facilitate the desorption of any trapped species, did not eliminate the peak. Moreover, this endothermic peak could not be attributed to the melting point of chitosan since a recrystallization peak did not occur by subsequent cooling. Furthermore, following the first scan, the characteristic peak was erased in the second scan (not shown here). Hence, this peak evident in the DSC traces characterizes the thermal behavior of an essentially dry chitosan. It is known that chitosan is the
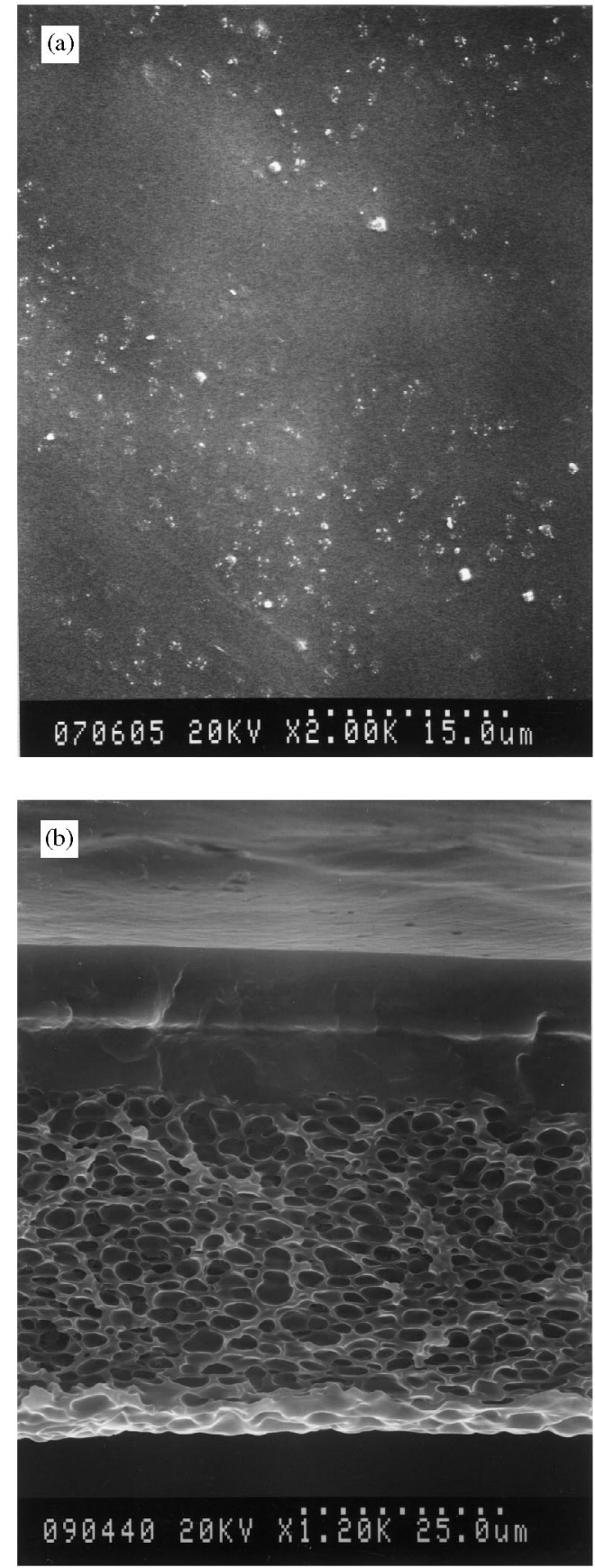

Fig. 1. SEM pictures of P-1 membrane: (a) top surface and (b) crosssection.

deacetylated form of chitin, which is a linear polymer of acetylamino-D-glucose. Therefore, the presence of this peak presumably results from the dissociation process of interchain hydrogen bonding of chitosan. Similar remarkable endotherms have been reported to occur in collagen by Sarti and Scandola [22], and this behavior has been related to the denaturation of order domains of proteins.

The DSC curve of the PVA/chitosan blend in the P-2 membrane shows the thermal properties of the two main 

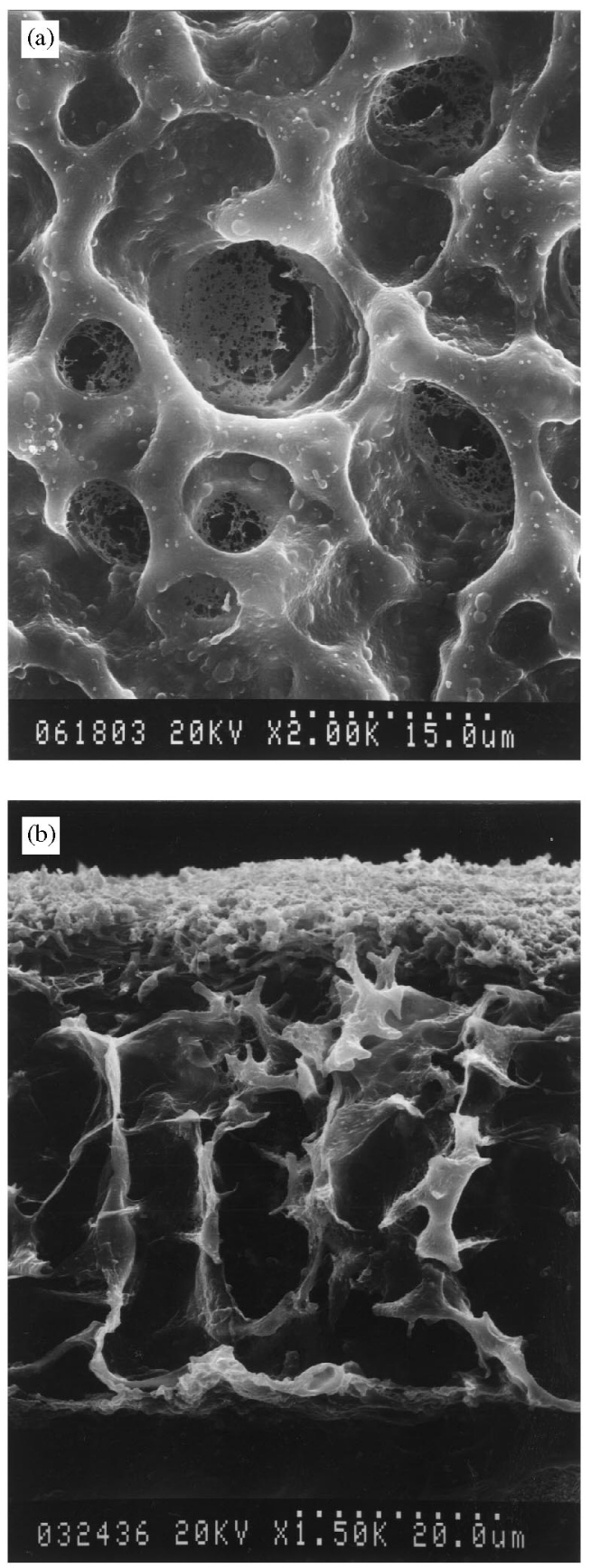

Fig. 2. SEM pictures of P-2 membrane: (a) top surface and (b) crosssection.

polymers: a glass transition temperature of $\mathrm{PVA}$ at $70^{\circ} \mathrm{C}$, a melting point of PVA at $225^{\circ} \mathrm{C}$ and a dissociation temperature of chitosan at $150^{\circ} \mathrm{C}$. The characteristic peak of chitosan does not seem to be affected by the blending process with PVA. But this distinctly similar peak occurs at a temperature $5^{\circ}$ lower than in the chitosan. In addition, the glass transition temperature of PVA also shifts to a temperature $5^{\circ}$ lower than in the PVA. These phenomena indicate that PVA and chitosan form a weak hydrogen-bonding interaction between

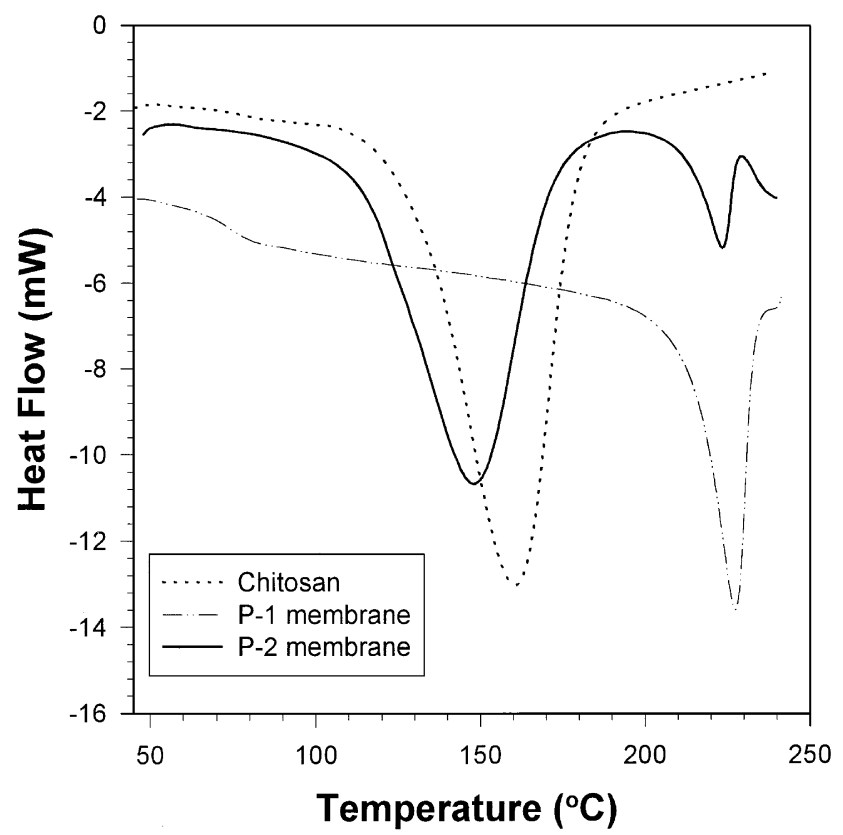

Fig. 3. DSC curves (first scan) of chitosan, P-1 and P-2 membranes.

them. Moreover, the melting peak of PVA at $225^{\circ} \mathrm{C}$ does not shift, suggesting that the crystal morphology be kept up after blending with chitosan. However, the lower endothermic peak at $225^{\circ} \mathrm{C}$ in the $\mathrm{P}-2$ curve than that in $\mathrm{P}-1$ curve suggests the PVA crystallization is decreased after blending with chitosan. These indicate good evidence that chitosan and PVA are immiscible at the molecular level in the blended membrane, whereas the combination of two polymer chains of constitutionally different features is revealed. Therefore, the two components in the P-2 membrane contribute independently to the blend properties. This consists with the P-2 membrane structure (Fig. 2) because the absence of efficient polymer-polymer interaction between PVA and chitosan results in the particular phase separation during the membrane formation.

The change in chemical structure of the membrane surface was investigated by ESCA. The P-1 membrane surface shows carbon (binding energy, ca. $288 \mathrm{eV}$ ) and oxygen (binding energy, ca. $535 \mathrm{eV}$ ) peaks, as expected in Fig. 4a. However, for the P-2 membrane, the result of ESCA shows carbon, oxygen, and nitrogen (binding energy, ca. $402 \mathrm{eV}$ ) peaks present in the Fig. $4 \mathrm{~b}$. The surface of P-2 membrane is enriched with nitrogen atoms, which should be from the amine group $\left(-\mathrm{NH}_{2}\right)$ of chitosan, this reflects that chitosan molecules are selectively present at the surface in the course of preparation of the membrane. Since the outermost surface molecules of a biomaterial directly interface with the body, the biocompatibility of the P-2 membrane will be different from that of the P-1 membrane.

The objective of this work is to investigate the functional properties of PVA membrane by blending with 


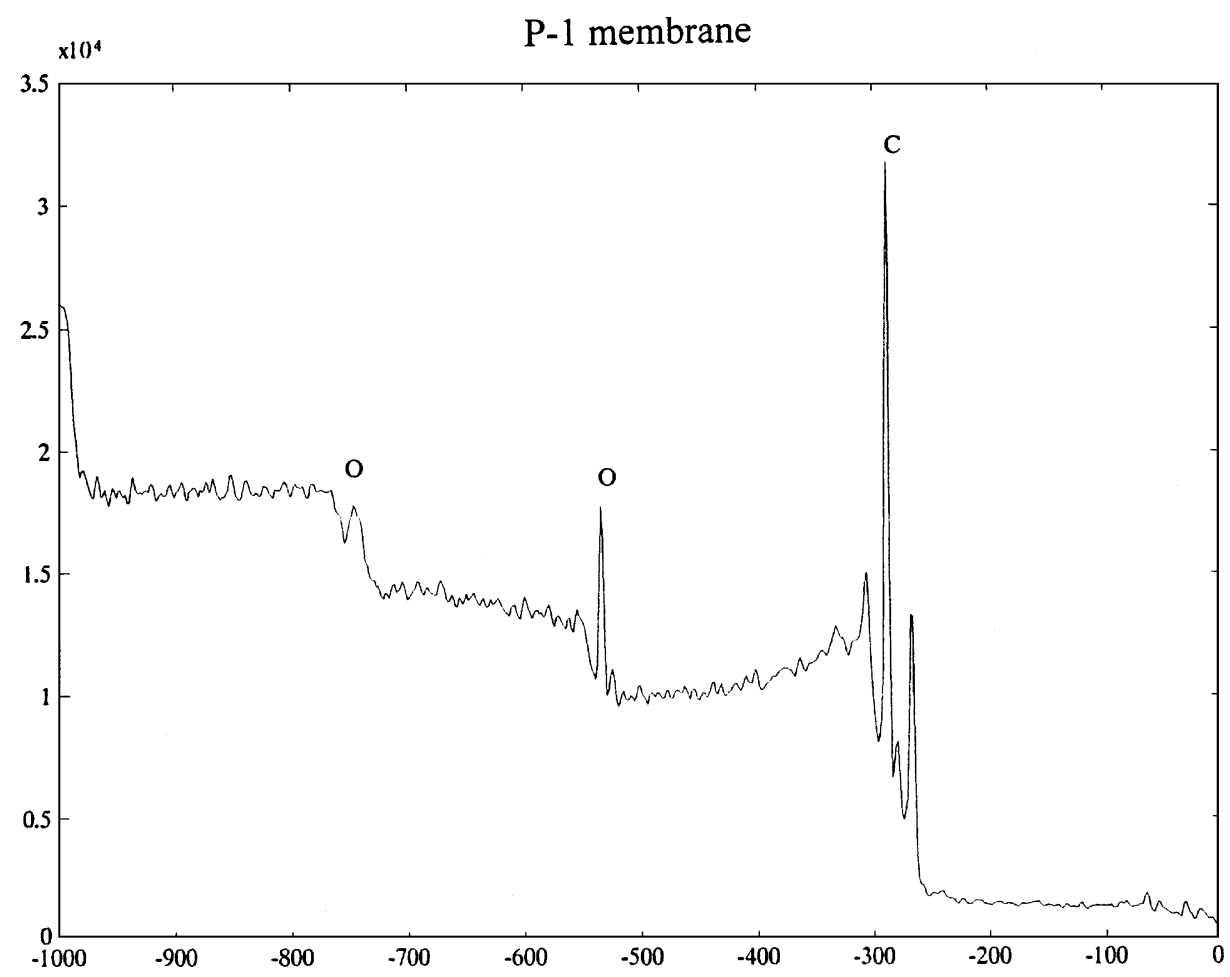

(a)

Binding Energy (eV)

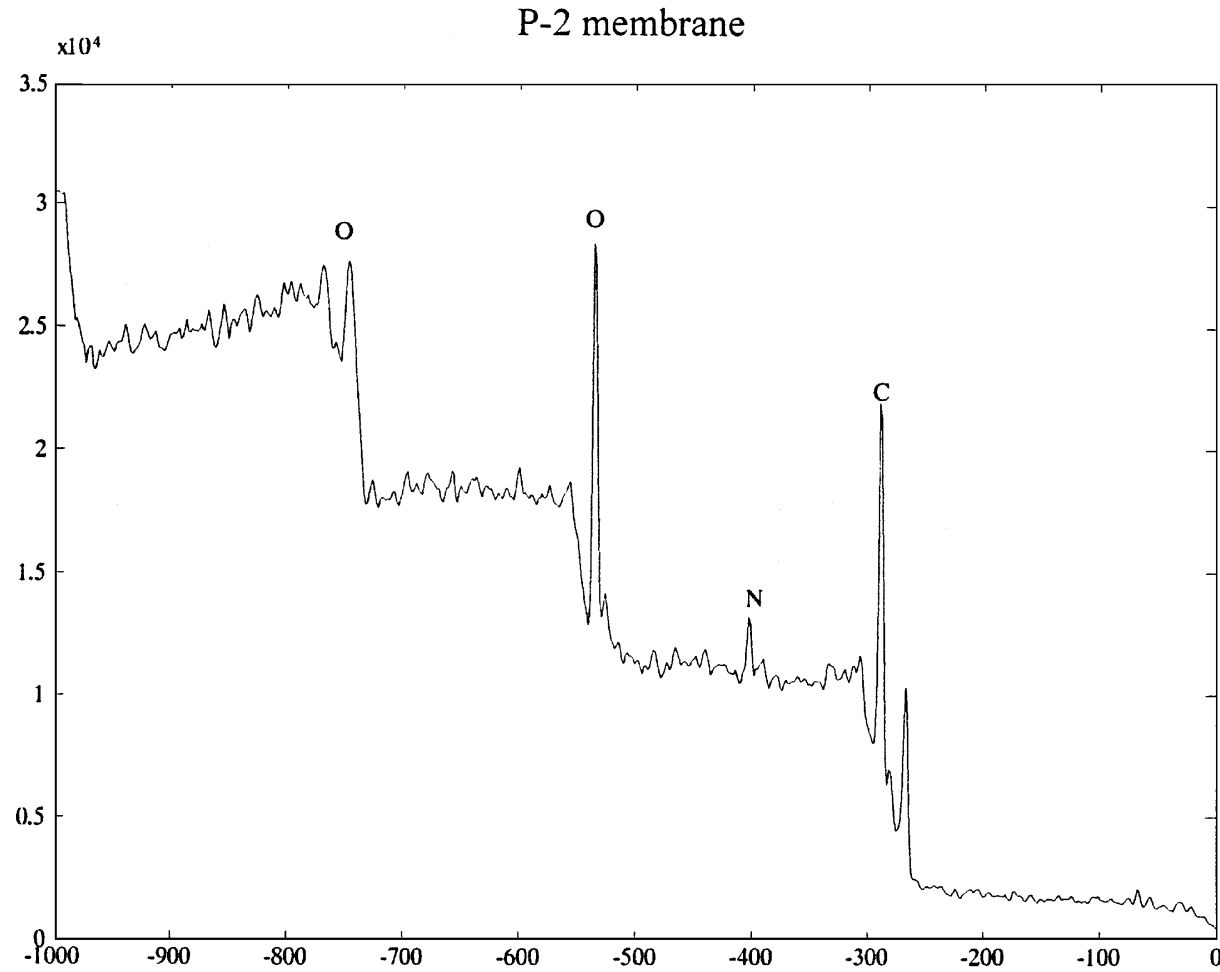

(b)

Binding Energy (eV)

Fig. 4. ESCA graphs of (a) P-1 and (b) P-2 membranes.

chitosan. From these results, both physical structures and chemical properties of PVA membranes are altered in the P-2 membrane. Therefore, the behavior of fibro- blasts on the P-1 and P-2 membranes were studied to evaluate the effect of the PVA/chitosan blend on the culture fibroblast in vitro. 


\subsection{Cell morphology}

The cellular behavior on a biomaterial is an important factor determining the biocompatibility of a biomaterial. After cells contact biomaterials, cells will undergo their morphological changes to stabilize the cell-material interface. The whole process of adhesion and spreading consists of cell attachment, filopodial growth, cytoplasmic webbing, flattening of the cell mass and the ruffling of peripheral cytoplasm progressing was in a sequential fashion [8]. Figure 5 shows the morphology of fibroblasts cultured on these two membranes for $4 \mathrm{~h}$. It can be seen that the cultured cells show clear morphologies in different progress. In Fig. 5a, the morphological type of fibroblast on the surface of P-1 membrane is just only in adhesion stage. At this time, cells are still spherical with microvilli-like projections in appearance. However, at the same culturing period, SEM examination shows that the fibroblasts with flattened morphology are in the stage of ruffling of peripheral cytoplasm on the surface of P-2 membrane; see Fig. 5b. Qualitatively, the P-2 membrane is more favorable for the cell culture than the P-1 membrane. Although exactly what stimuli are responsible for the observed phenomenon remains to be determined, the effect of the addition of chitosan into the P-2 membranes on the fibroblast culture must be involved.

Figure 6 shows the morphology of fibroblasts cultured on these two membrane surfaces for $1 \mathrm{~d}$. Following the initial stage of cell attachment, cytoplasmic webbing of the cells attaching on the surface of P-2 membrane are seen and filopodial progressively extends centrifugal; see Fig. 6b. At this time, cells on the P-2 membrane could be considered completely flattened and well spread. Furthermore, the stage of cell fusion is found on this membrane. In contrast, centrifugal growth of filopodia and cytoplasmic webbing are not evident for fibroblasts on the surface of P-1 membrane. The morphological type of fibroblasts is just only in the early stage of cell attachment. In addition, the SEM pictures seem to reveal that the cell number of P-1 membrane is less than that on the P-2 membrane. However, one has to be careful while making conclusions from SEM pictures since the selection of the view from a microscope certainly changes the cell number on the membrane. Nevertheless, the difference of the cell number between these two membranes is so clear that obviously the effect of the addition of the chitosan into the P-2 membrane remains observable, which could be confirmed by MTT assay and described in the next section.

Fibroblast morphology was also compared on the prepared membranes after culturing for 4 days, as indicated in Fig. 7. Similarly, significant difference in cell morphology and cell number are found between on the P-1 and P-2 membranes. On the P-2 membrane, a lot of cells are apparent and the cells exhibit the fusion phenomenon significantly. In contrast, cells on the P-1
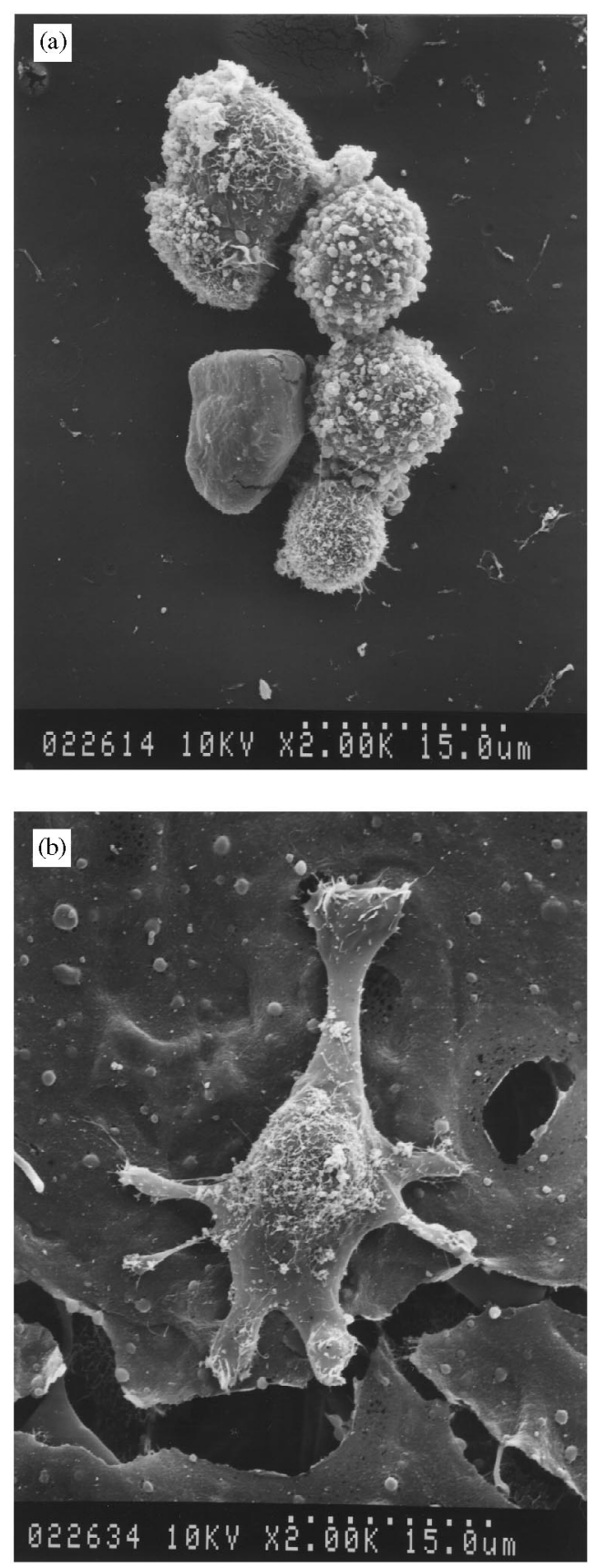

Fig. 5. SEM pictures of fibroblasts cultured on the (a) P-1 and (b) P-2 membranes after $4 \mathrm{~h}$.

membrane appear to lose their function. From Figs. 5-7, it confirms that several stages can be noted during cell culture on the P-1 and P-2 membranes. Therefore, it clearly suggests that the P-2 membrane had better surface for the culture of fibroblasts, which is related to the presence of chitosan in the PVA membrane.

\subsection{MTT assay}

MTT reagent is a pale yellow substrate which produces a dark blue formazan product when incubation 

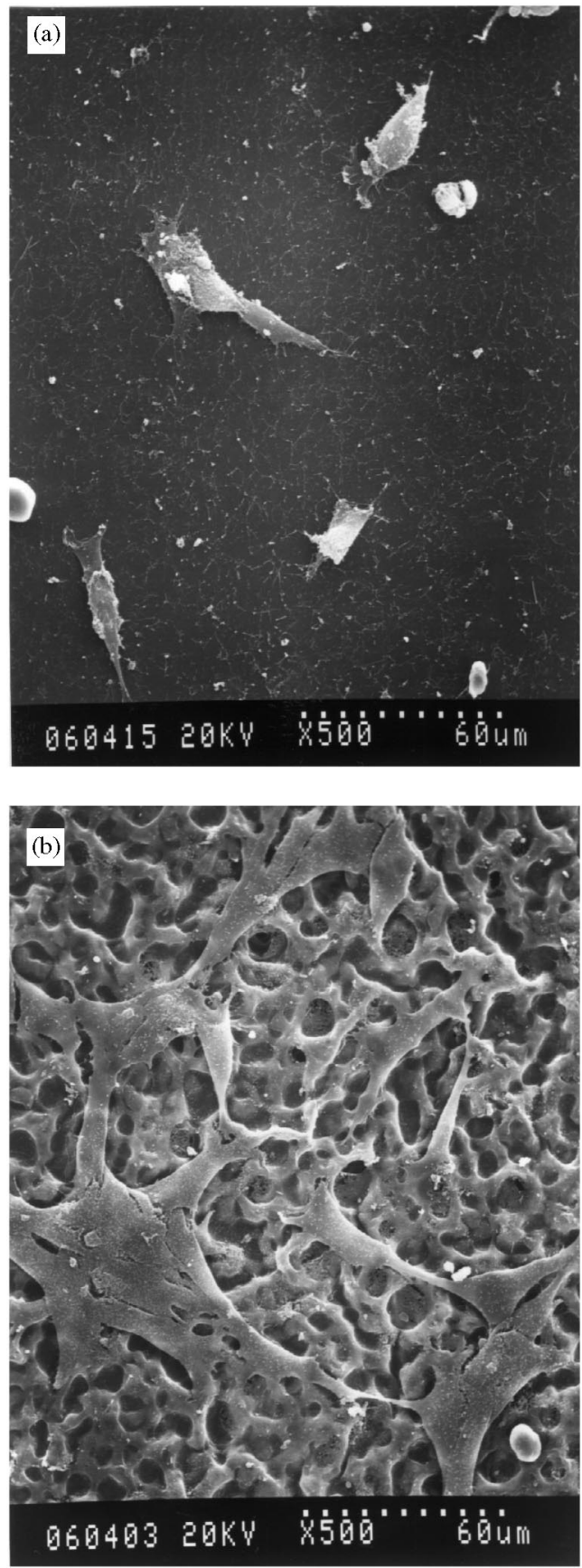

Fig. 6. SEM pictures of fibroblasts cultured on the (a) P-1 and (b) P-2 membranes after $1 \mathrm{~d}$.

with viable cells. Therefore, the level of the reduction of MTT into formazan can reflect the level of cell metabolism. Figure 8 shows the time course of formazan accumulation ( $\%$ of control) for the P-1 and P-2 membranes. Control group is the tissue culture polystyrene dish with a Teflon ring. Formazan absorbance indicates that fibroblasts seeded onto the P-1 and P-2 membranes were able to convert the MTT into a blue formazan product. The tendency of these two curves is similar. However, the
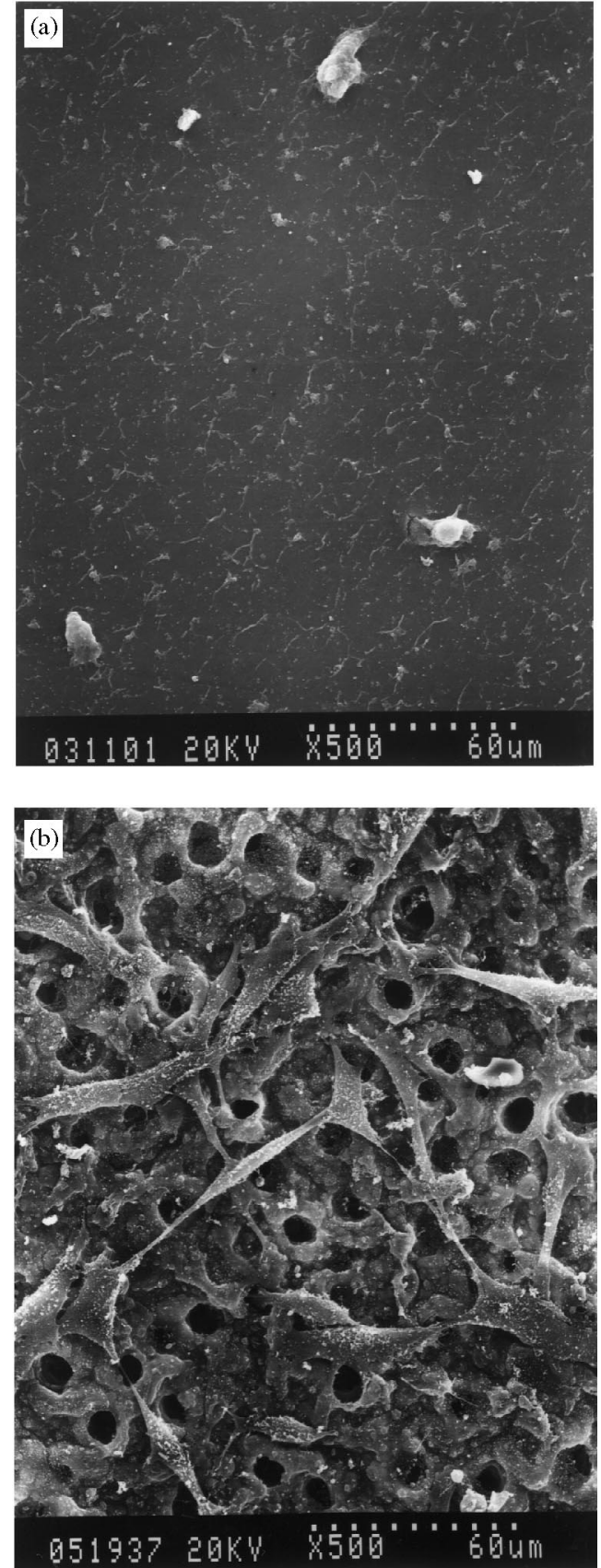

Fig. 7. SEM pictures of fibroblasts cultured on the (a) P-1 and (b) P-2 membranes after $4 \mathrm{~d}$.

number of cells on the P-1 membrane is significantly lower than on the P-2 membrane $(P<0.01)$ over a $4-\mathrm{d}$ period. Approximate $70-80 \%$ of cells adhered on the P-2 membrane relative to the control, but only about $30 \%$ cells adhered on the P-1 membrane relative to the control. Taken together, the MTT data correlate with the obvious morphological differences of fibroblasts on the P-1 and P-2 membranes by SEM observation (Figs. 5-7). 


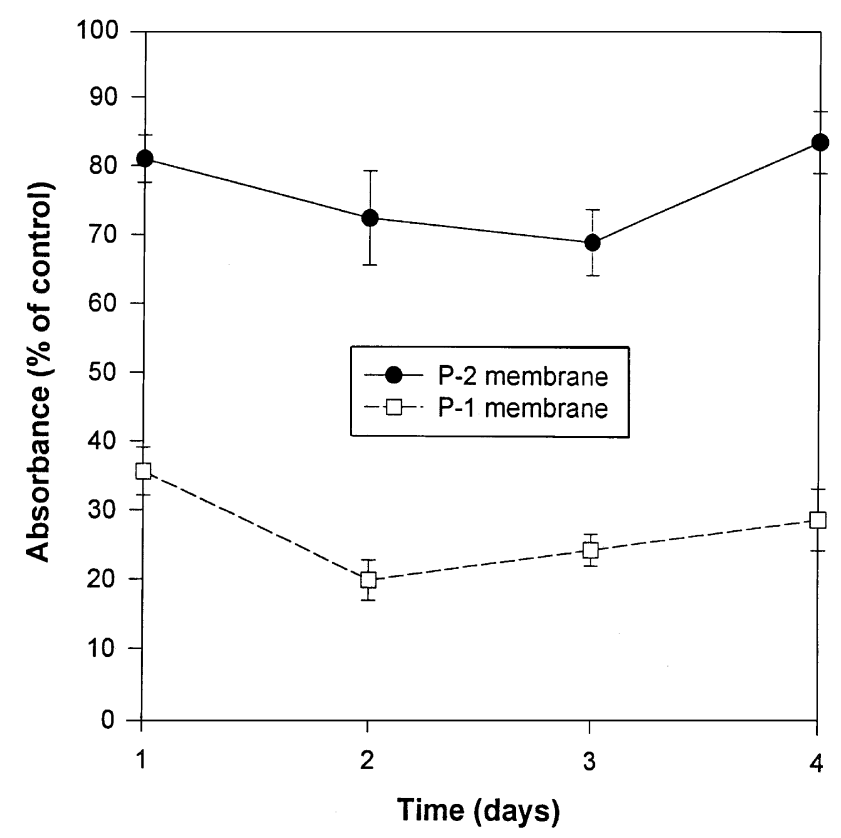

Fig. 8. MTT-tetrazolium assay. Formazan absorbance ( $\%$ of control) expressed as a function of time from fibroblasts seeded onto P-1 and P-2 membranes $(n=4)$. These data show a significant difference $(P<0.01)$ between P-1 and P-2 membranes at all time points.

The surfaces of the P-1 and P-2 membranes have different effects on the fibroblasts. It appears that cells on the P-1 membrane were able to attach but unable to follow this attachment with spreading. In contrast, when the membranes were blended by chitosan, they became substrates much like controls. The cells attached and spread on the chitosan-modified surfaces without apparent impairment of cell morphology. It has been demonstrated that some proteins either resident in serum or secreted by cells play an important role in adhesion and spreading of cells on substrates [23]. Thus, an alternative possible explanation for the better attachment and spreading of cells on the P-2 membrane is that mediating proteins were richly adsorbed and the adsorbed proteins took a configuration favorable for cell spreading. In contrast, fibroblasts grew more slowly on the P-1 membrane than on the P-2 membrane. It was suggested that this inhibited growth of fibroblasts on the P-1 membrane might be that protein-binding sits on the chitosan are not present or adsorbed proteins are distorted by the pure PVA surface. Therefore, it is both physical and chemical modifications that make the P-2 membrane an ideal candidate for a potential biomaterial.

In conclusion, this study demonstrated that PVA membranes were modified by blending chitosan, which led to the fibroblast adhesion and development. Therefore, PVA/chitosan blended biomaterials produced in this manner show the potential for providing new materials with enhanced properties for biomedical application.

\section{Acknowledgements}

The authors thank the National Health Research Institute and Department of Health of the Republic of China for their financial support for the project DOH 87-HR-635.

\section{References}

[1] Loeb S, Sourirajan S. Sea water demineralization by means of an osmotic membrane. Adv Chem Ser 1963;38:117.

[2] Young TH, Yao NK, Chang RF, Chen LW. Evaluation of asymmetric poly(vinyl alcohol) membranes for use in artificial islets. Biomaterials 1996;17:2139-45.

[3] Young TH, Chuang WY, Yao NK, Chen LW. Use of a diffusion model for assessing the performance of poly(vinyl alcohol) bioartificial pancreas. J Biomed Mater Res 1998;40:385-91.

[4] Inoue K, Fujisato T, Gu YJ, Burczak K, Sumi S, Kogire M, Tobe T, Uchida K, Nakai I, Maetani S, Ikada Y. Experimental hybrid islet transplantation: application of polyvinyl alcohol membrane for entrapment of islets. Pancreas 1992;7:562-8.

[5] Paul W, Sharma CP. Acetylsalicylic acid loaded poly(vinyl alcohol) hemodialysis membranes: effect of drug release on blood compatibility and permeability. J Biomed Sci Polymer Ed 1997; 8:755-64.

[6] Hara Y, Kamiya S, Nishioka K, Saishin M, Nakao S, Yamauchi A. Behavior of poly(vinyl alcohol) hydrogel in the vitreous body of albino rabbits. Nippon Ganka Gakkai Zasshi- Acta Societatis Ophthalmologicae Japonicae 1979;83:1478-85.

[7] Burczak K, Gamian E, Kochman A. Long-term in vivo performance and biocompatibility of poly(vinyl alcohol) hydrogel macrocapsules for hybrid-type artificial pancreas. Biomaterials 1996; 17:2351-6.

[8] Rajaraman R, Rounds DE, Yen SPS, Rembaum A. A scanning electron microscope study of cell adhesion and spreading in vitro. Exp Cell Research 1974;88:327-39.

[9] Inoue T, Cox JE, Pilliar RM, Melcher AH. Effect of the surface geometry of smooth and porous-coated titanium alloy on the orientation of fibroblasts in vitro. J Biomed Mater Res 1987;21:107-26.

[10] Iio K, Minoura N, Aiba S, Nagura M, Kodama M. Cell growth on poly(vinyl alcohol) hydrogel membranes containing biguanido groups. J Biomed Mater Res 1994;28:459-62.

[11] Tamada Y, Ikada Y. Fibroblast growth on polymer surfaces and biosynthesis of collagen. J Biomed Mater Res 1994;28:783-9.

[12] Mori T, Okumura M, Matsuura M, Ueno K, Tokura S, Okamoto Y, Minami S, Fujinaga T. Effects of chitin and its derivatives on the proliferation and cytokine production of fibroblasts in vitro. Biomaterials 1997;18:947-51.

[13] Rao SB, Sharma CP. Use of chitosan as a biomaterial: studies on its safety and hemostatic potential. J Biomed Mater Res 1997;34:21-8.

[14] Chang S, Puryear J, Funkhouser EA, Newton RJ, Cairney J. Cloning of a cDNA for a chitinase homologue which lacks chitinbinding sites and is down-regulated by water stress and wounding. Plant Mol Biol 1996;31:693-9.

[15] Chandy T, Sharma CP. Chitosan - as a biomaterial. Biomater Artif Cells Artif Organs 1990;18:1-24.

[16] Okamoto Y, Minami S, Matsuhashi A, Sashiwa H, Saimoto H, Shigemasa Y, Tanigawa T, Tanaka Y, Tokura S. Application of polymeric N-acetyl-D-glucosamine (chitin) to veterinary practice. J Vet Med Sci 1983;55:743-7.

[17] Yunlin G, Xiaofei L, Yingping Z, Kangde Y. Study of phase behavior on chitosan/viscose rayon blend film. J Appl Polymer Sci 1998;67:1965-72. 
[18] Sakurada I. Polyvinyl alcohol fibers. NY: Marcel Dekker, 1985.

[19] Mosmann T. Rapid colorimetric assay for cellular growth and survival: application to proliferation and cytotoxicity assays. J Immunol Meth 1983;65:55-63.

[20] Apicella A, Hopfenberg HB, Piccarolo S. Low temperature thermal aging of ethylene vinyl alcohol copolymers. Polymer Eng Sci 1982;22:382-7.
[21] Wu LG, Zhu CL, Liu M. Study of a new pervaporation membrane. Part 2. Performance test and dialysis of the new membrane. J Memb Sci 1994;90:207-12.

[22] Beatrice S, Mariastella S. Viscoelastic and thermal properties of collagen/poly(vinyl alcohol) blends. Biomaterials 1995;16:785-92.

[23] Carbonetto ST, Gruver MM, Turnerr DC. Nerve fiber growth on defined hydrogel substrates. Science 1982;216:897-9. 